\title{
Influence of fault zone maturity on fully dynamic earthquake cycles
}

\section{Key Points:}

- We simulate earthquake cycles in fault zones with coseismic damage and interseismic healing.

- There are more surface-rupturing events with regular recurrence intervals as fault zones become more mature.

- Healing of immature fault zones promotes slow-slip events within the seismogenic zone causing partial ruptures.

This paper is a non-peer reviewed preprint submitted to Geophysical Research Letters.

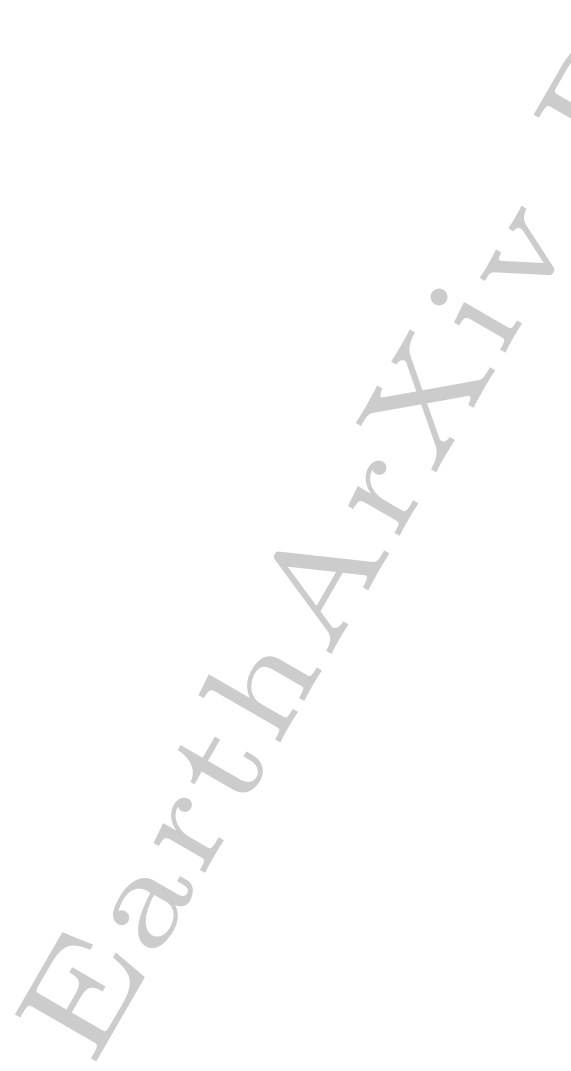

Corresponding author: Prithvi Thakur, prith@umich.edu 


\begin{abstract}
We study the mechanical response of two-dimensional vertical strike-slip fault to coseismic damage evolution and interseismic healing of fault damage zones by simulating fully dynamic earthquake cycles. Our models show that fault damage zone structure evolution during the seismic cycle can have pronounced effects on the mechanical behavior of locked and creeping fault segments. Immature fault damage zones promote small and moderate subsurface earthquakes with irregular recurrence intervals and abundance of slow-slip events during the interseismic period. In contrast, mature fault damage zones host pulse-like earthquake ruptures that can propagate to the surface and extend throughout the seismogenic zone, resulting in large stress drop, characteristic rupture extents, and regular recurrence intervals. Our results suggest that interseismic healing and coseismic damage accumulation in fault zones can explain the observed differences of earthquake behaviors between mature and immature fault zones and indicate a link between regional seismic hazard and fault structural maturity.
\end{abstract}

\title{
Plain Language Summary
}

Fault zones are geometrically complex network of fractures with slip surfaces that are capable of hosting earthquakes. This network evolves through time as more and more earthquakes generate damage in the vicinity of the slip surfaces. We use numerical models to simulate different stages of fault-slip behavior including earthquakes, slow-slip events, and aseismic creep on a planar fault surrounded by a damage zone. This damage zone is prescribed to accumulate damage after an earthquake and heal during the quiet periods between earthquakes. Depending on the compliance (i.e., the ability to accommodate deformation) of the damage zone with respect to the surrounding host rock, a fault zone can be at different stages of its maturity, with higher compliance corresponding to a more mature fault zone. We find that an immature fault zone tends to produce smaller earthquakes whose slip does not reach the surface of the earth, and the duration between earthquakes is irregular. As fault zones become more mature, earthquakes can rupture to the surface and occur more regularly. Our results highlight a link between regional seismic hazard and fault structural maturity.

\section{Introduction}

Active faults are usually surrounded by narrow regions of localized deformation extending several hundred meters to a few kilometers in width across the fault. This deformation zone consisting of a dense fracture network is macroscopically viewed as an elastic layer with low seismic wave velocities and referred to as a fault damage zone (Ben-Zion \& Sammis, 2003). The strength of the fault damage zone evolves throughout the seismic cycle, but the details of the evolution mechanism and the nature of this evolution remain elusive.

Fault zone maturity can be defined and quantified by the total slip accumulated over time in field geologic and geodetic studies (Dolan \& Haravitch, 2014), with larger slip corresponding to higher maturity. Fig. 1 shows a conceptual model of how a strike-slip fault system may evolve through multiple earthquake cycles. Immature fault zones (Fig. 1a) are characterized by a distributed network of damage, and as the fault zone matures (Fig. 1c), the damage becomes localized. The faulting itself becomes more localized, transitioning from multiple and discontinuous slip surfaces to a more throughgoing fault. Other parameters such as the total fault length, the slip rate, and the initiation age have also been used to determine fault zone maturity (Perrin et al., 2016). However, the surface slip expression for immature faults usually underestimate slip at depth by about $10 \%$ to $60 \%$ (Dolan \& Haravitch, 2014). Perrin et al. (2016) have shown that structural maturity of a strike-slip fault zone is well correlated with the seismic wave velocity of near-fault materials, which decreases as the fault zone becomes progressively more mature. Such velocity reductions are 
well documented along mature fault zones such as the San Andreas fault zone (Y.-G. Li et al., 2006; M. A. Lewis \& Ben-Zion, 2010), San Jacinto fault zone (M. Lewis et al., 2005), Nojima fault zone (Mizuno et al., 2008), and Wenchuan fault zone (Pei et al., 2019). Examples of immature fault zones that exhibit less evidence of localized damage include the northern part of the San Andreas fault zone (Waldhauser \& Ellsworth, 2002), the Bam fault in Iran (Fielding et al., 2009), the Jiuzhaigou earthquake near Kunlun fault zone in China (Y. Li et al., 2020), and Peloponnese fault zone in Greece (Feng et al., 2010). Previous studies have shown that a more compliant or mature fault damage zone enables ruptures to propagate as slip pulses (Harris \& Day, 1997; Huang \& Ampuero, 2011; Huang et al., 2014; Thakur et al., 2020; Idini \& Ampuero, 2020). Geodetic observations (e.g., Goldberg et al. (2020); Feng et al. (2010)) have shown earthquake slip distributions are complex in an immature fault zone, and they become more uniform as the fault zone matures. Understanding the long-term earthquake behavior during the structural evolution of the fault damage zone is key to unraveling the locations, recurrence intervals, stressing history, and the probability of subsequent earthquakes in an active fault zone.

Observations of seismic wave velocity changes within the fault damage zone $(<1 \mathrm{~km}$ from the fault; e.g., Vidale and Li (2003); Y.-G. Li et al. (2003, 2006); Wu et al. (2009); Peng and Ben-Zion (2006); Zhao and Peng (2009); Roux and Ben-Zion (2014)) documented a sharp decrease in pressure- and shear-wave velociiesy following earthquakes as well as a subsequent logarithmic increase in wave velocity with time. Other observations further away from the fault zone (e.g., Taira et al. (2009); Chen et al. (2015); Pei et al. (2019)) revealed coseismic reduction and interseismic increase of seismic wave velocities in the surrounding region. Laboratory experiments have shown/similar change in seismic wave velocities (P. A. Johnson \& Jia, 2005; Kaproth \& Marone, 2014; Snieder et al., 2016) wherein they observe compaction during holds (i.e., interseismic period) and dilation during fault slip (i.e., seismic events). Mechanisms for damage accumulation in active fault zones are likely a combination of processes including dilation, compaction, cracking, shear driven pulverization, and fabric generation (Gratier et al., 2003). The observed coseismic seismic velocity drop is potentially related to brecciation, cataclasis, and damage accumulation, implying a magnitude dependence of this velocity drop (Y.-G. Li et al., 2003; Rubinstein \& Beroza, 2005; Brenguier et al., 2008).

During the interseismic period, time-dependent fault zone healing may occur due to a combination of rheological restrengthening, inelastic strain, mineral precipitation, and fluid pressure recovery (Vidale \& $\mathrm{Li}, 2003$ ). There is some debate on whether this healing time is significant in contributing to fault zone stress redistribution and therefore influencing longterm seismicity (Vidale \& Li, 2003; Mizuno et al., 2008). It is hard to accurately quantify fault zone healing time because it requires long-term continuous monitoring of seismic wave velocities. Active seismic studies along the Landers fault zone (Vidale \& Li, 2003) and Longmenshan fault zone-(Pei et al., 2019) suggest that it may take years or decades to heal completely, whereas other studies (Peng \& Ben-Zion, 2006; Mizuno et al., 2008; Wu et al., 2009) suggest that the healing time may not be longer than the typical timescales of postseismic afterslip, i.e., a couple of months. Another study by Roux and Ben-Zion (2014) along the North Anatolian Fault suggests a recovery rate over a timescale of few days. It is worthwhile noting that some of these studies may have a lower spatial resolution than others which might affect the inference of fault zone recovery rate.

We use numerical simulations to understand the effects of fault zone damage accumulation after multiple cycles of earthquakes and healing during the interseismic period on a two-dimensional vertical strike-slip fault. We model the fault zone structure evolution as changes in the shear wave velocity of an elastic layer surrounding a strike-slip fault. This elastic fault damage zone has a lower shear wave velocity, and therefore, a lower rigidity compared to the surrounding host rock. We assume a constant density in our numerical simulations as the changes in shear-wave velocity has a more significant effect on the rigidity of the material. Throughout the remainder of this article, we will use the term "rigidity 
ratio", which is the percentage ratio of the fault zone shear modulus to the host rock shear modulus, to parameterize the fault zone evolution through time. Fig. 1b shows a representative rigidity ratio evolution through time. We constrain the coseismic damage accumulation and the rate of interseismic healing using shear-wave velocity observations from Wenchuan (Pei et al., 2019), Landers (Vidale \& Li, 2003), Nojima (Mizuno et al., 2008), and North Anatolian Fault zones (Peng \& Ben-Zion, 2006). We describe the numerical procedure and the fault zone healing mechanism in section 2 and appendix A. The results of our models are described in section 3 . We show that an immature fault zone tends to produce more slow-slip events and irregular earthquake sequences with predominantly subsurface events. In contrast, a more mature fault damage zone tends to produce a more regular sequence of earthquakes with a combination of surface-reaching and subsurface events. In section 4, we discuss the implications of our results for earthquake cycle behaviors of strike-slip fault zones.

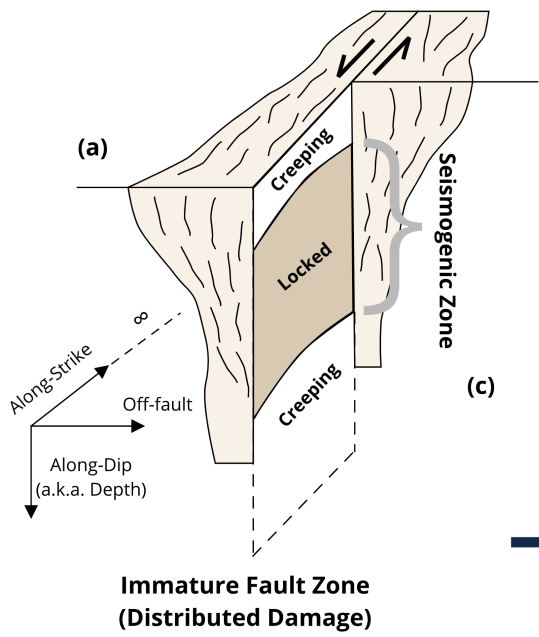

(b) Damage Evolution Model

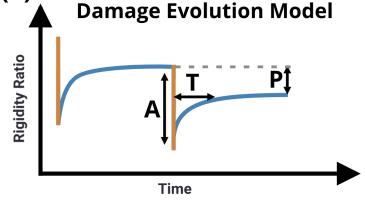

(c)

$\mathbf{A}=$ Coseismic Damage Accumulation $\mathbf{P}=$ Permanent Damage after an Earthquake $\mathbf{T}=$ Interseismic Healing Time

(Distributed Damage)

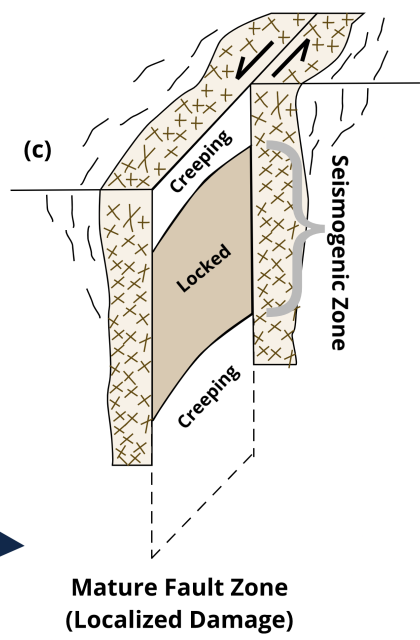

Figure 1. A conceptualized evolution of a fault damage zone through multiple earthquake sequences for strike-slip fault systems. (a) Schematic of an immature fault zone with distributed damage increases towards the surface. (b) Parameters considered for an elastic damage evolution model, showing the prescribed change in the rigidity ratio (ratio of shear modulus in damage zone to that in the host rock) through time. (c) Schematic of a mature fault zone with localized damage and a dense fracture network.

\section{Model Description}

We use two-dimensional earthquake cycle models of strike-slip faults with mode III rupture where the displacement is out of the plane of interest and stresses and friction vary with depth. For simplicity, we use a narrow fault-parallel layer as a proxy for the damage zone and its geometry remains constant throughout the simulated sequence. This is equivalent taking a vertical cross-section across Fig. 1c, and the fault zone maturity in the damage evolution model corresponds to the change in rigidity ratio without changing the geometry of the fault zone (Fig. 1b). The frictional properties and initial conditions are described in detail in Appendix A, whereas here we will focus the discussion on fault zone properties.

Since there are very few long-term observations (10,000-100,000 years) documenting the changes in permanent damage through multiple earthquake cycles, we focus on simulating 
earthquake cycles at different stages of the fault zone maturity for several hundred years, including an immature stage and a mature stage, both of which accumulate no permanent damage. We also consider a transition stage which incorporates permanent damage, i.e., a reduction in rigidity after each earthquake. The distinction between immature and mature fault zones in our models depends on the rigidity ratio of the damage zone to the host rock. Typically, larger velocity reductions (35\% to $50 \%)$ and lower rigidities (25\% to $45 \%$ of host rock) are measured around mature fault zones, whereas smaller velocity reductions ( $8 \%$ to $10 \%$ ) and higher rigidities ( $80 \%$ to $90 \%$ of host rock) are measured around immature fault zones (Perrin et al., 2016). Based on these seismic wave velocity measurements, we choose a rigidity ratio changing between $80 \%$ and $85 \%$ of host rock for the immature fault zone and a rigidity ratio changing between $40 \%$ and $45 \%$ of the host rock. While mature fault zones can have lower rigidities as well, the chosen values lie well within what is observed for mature and immature fault zones.

Another important parameter is the coseismic velocity drop. While its value is not well constrained by observations and can vary significantly $(0.1 \%$ to $5 \%)$ between different fault zones such as Parkfield (Y.-G. Li et al., 2006), Wenchuan (Pei et al., 2019), and Landers (Y.-G. Li et al., 2003), it is dependent on the size of the earthquake with smaller earthquakes showing smaller coseismic drop. Since our simulations are two-dimensional and do not have any along-strike constraints on the earthquake size, we use a magnitudeindependent coseismic damage accumulation of $5 \%$ rigidity change in order to facilitate a better comparison between different simulation cycles.

\section{Results}

We have tested a range of parameters in our simulations that account for fault zone maturity, coseismic damage accumulation, and healing time. Here the fault zone maturity can be described by the initial rigidity ratio (Fig, 1b). These parameters are discussed in the Appendix A. We choose to show the representative cases for a healing time of 8 years and a coseismic velocity drop of $5 \%$ in the following subsections for brevity. Changing these parameters (e.g., a healing time between 1 and 20 years) have some effects on the location and timing of individual earthquakes but does not affect the overall interpretation of our results.

\subsection{Effects of fault damage zone maturity}

The initial rigidity ratio of fault damage zones with respect to the surrounding host rock can have significant effects on seismicity evolution. A higher initial rigidity ratio implies a less mature fault zone and vice versa. While keeping the permanent damage at zero, we compare an immature fault zone evolution characterized by rigidity ratio changing between $80 \%$ and $85 \%$, against a mature fault zone evolution characterized by rigidity ratio changing between $40 \%$ and $45 \%$ (Figs. $2 \mathrm{a}$ and b). For the sake of simplicity, the fault zone accumulates damage by the same amount irrespective of the earthquake size.

For a constant healing time, a mature fault zone tends to show more regular earthquake sequences with full (surface-reaching) ruptures, whereas a less mature fault zone shows irregular earthquake sequences with partial (subsurface) ruptures and more slow-slip events (Figs. 2c and d). The cumulative slip demonstrates events with variable sizes and depths throughout the seismogenic zone, but we do not see ruptures spanning the entire seismogenic region in the immature fault zone. Instead, we only see ruptures extending across a fraction of the seismogenic zone, and these partial ruptures persist throughout multiple seismic cycles. This phenomenon of partial ruptures occurs only in immature fault zones with healing, which tend to have crack-like ruptures and overall lower slip velocities. In contrast, mature fault zones exhibit higher slip-velocities and pulse-like ruptures, which tend to produce surface-reaching ruptures. Such pulse-like ruptures can be identified by looking 
at the cumulative slip of earthquake cycles in mature fault zones (Fig. 2d), where the final slip distribution is nearly flat, a characteristic of pulse-like ruptures (Heaton, 1990).

We measure shear stress before and after a representative earthquake from each of these simulations to understand the depth distribution of stress drop and the mechanisms accounting for different earthquake behaviors in mature and immature fault zones. Figs. 2e and $f$ show the depth distribution of shear stress for an earthquake in an immature fault zone and a mature fault zone, respectively. We see that the mature fault zone exhibits a large, uniform stress drop along the fault dip (Fig. 2f) such that stress peaks after the earthquake are concentrated only towards the edges of the velocity-weakening segment due to ruptures propagating throughout the seismogenic zone. On the other hand, the immature fault zone (Fig. 2e) results in a partial stress drop as the rupture is arrested before reaching the edges of the asperity. In this context, a partial stress drop refers to the stresses being released only in a small portion of the velocity-weakening segment along the fault. The partial stress drop in immature fault zones leads to residual stress peaks concentrated within the velocityweakening region, which may cause subsequent ruptures or slow-slip events near those stress peaks. As discussed in more detail in section 3.2, the slow-slip events can delay the next earthquake rupture and result in irregular recurrence intervals between earthquakes.

We also include permanent damage after each earthquaké in our model to demonstrate the transition from an immature fault zone to a mature fault zone (i.e., $\mathrm{P}$ is nonzero in Fig. 1b). While faults in nature need several tens of thousands of years to transition from immature to mature stages, it is not computationally feasible to perform such simulations with full inertial effects. The choice of the amount of coseismic velocity reduction and interseismic healing in our simulations allows the transition from immature to mature fault zones within 300-400 years. Fig. A1 shows the accumulated slip contours for the earthquake cycle in this scenario. We begin with an initial rigidity ratio of $90 \%$ and drop it down by $5 \%$ after each earthquake (Fig. A1). We allow the fault to recover $4 \%$ of the rigidity during the interseismic period therefore accommodating a permanent damage of $1 \%$ rigidity reduction after each earthquake, though smaller recovery percentages may be achieved if the next earthquake occurs before the fault has healed completely (Fig. A1b). We see a progressive increase in the rupture length from partial to full ruptures as the fault zone becomes more mature (Fig. A1a). We distinguish between an immature and a mature fault damage zone based on when we start observing surface-reaching events that rupture the entire seismogenic zone. Surface-reaching ruptures become prevalent when the rigidity ratio falls below $60 \%$ of the host rock. Furthermore, earthquakes become more regular and frequent as the fault zone matures. This simulation informs us that the transition from immature to mature fault zone is gradual, and we can see a mixture of surface-reaching and subsurface events during this transition stage.

\subsection{Effects of healing: slow-slip events and irregularity in recurrence inter- vals}

Interseismic healing has significant effects on the dynamics of earthquakes and aseismic fault-slip, including creep accumulation within the nominally velocity-weakening region, inhibition of surface-reaching events, restriction of earthquake sizes, and generation of slowslip events also within the velocity-weakening region. Here we discuss the effects of healing in an immature fault zone in more detail and demonstrate how slow-slip events affect seismicity by comparing a simulation with fault zone rigidity ratio ranging between $60 \%$ and $65 \%$ against a fault zone with the same initial rigidity ratio but without healing (i.e., a constant rigidity ratio of $60 \%$ ). This range of rigidity ratio still lies in the immature fault zone parameter space discussed in the previous section but leads to fewer slow-slip events compared to the $80 \%$ to $85 \%$ range. It allows us to analyze the healing effect and slow-slip events more clearly. 
(a)

Immature fault damage zone

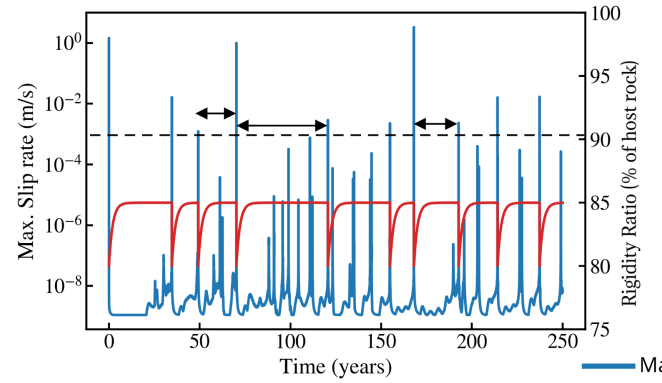

$\longleftrightarrow$ Irregular recurrence

(c)

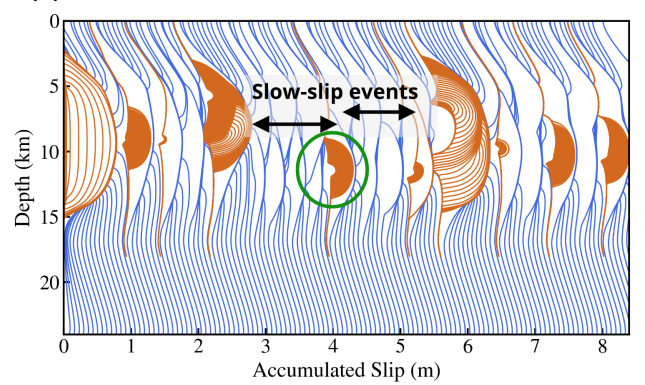

(e)

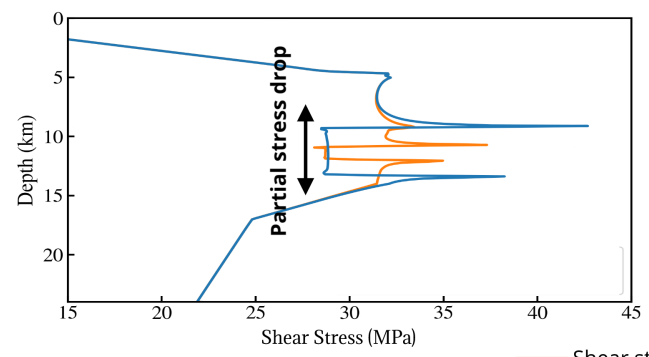

(b)

Mature fault damage zone

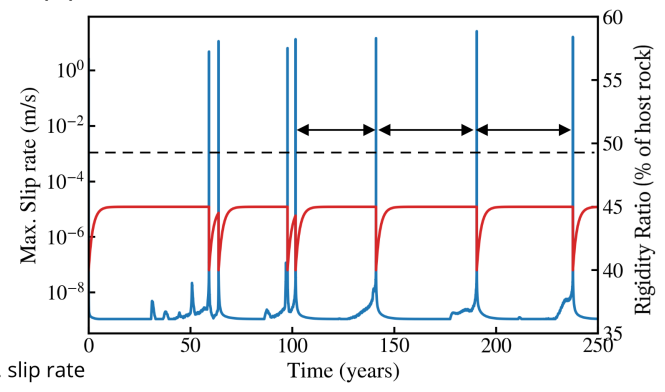

$\longleftrightarrow$ Regular recurrence

(d)

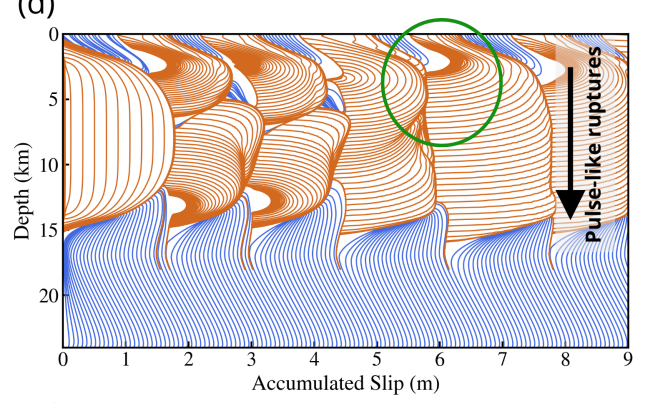

(f)

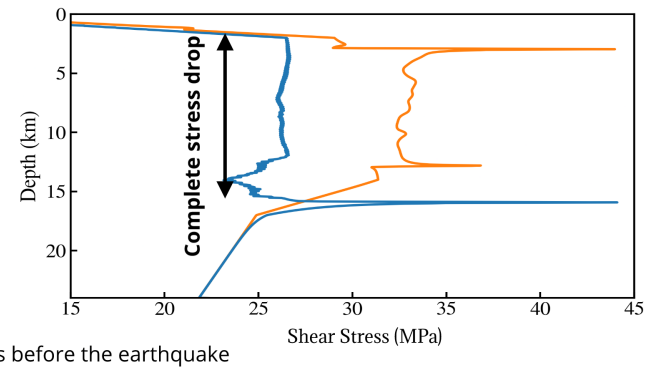

Figure 2. Immature vs mature fault damage zone. (a-b) The evolution of slip-rate function (blue) and the rigidity ratio (red) through time. (c-d) Cumulative slip through earthquake sequences shown along depth in mature and immature fault zones. The orange lines are plotted every 0.1 seconds during earthquakes, and the blue lines are plotted every year during interseismic periods. (e-f) The on-fault shear stress before and after a representative earthquake for each case (circled in green in (c) and (d)) demonstrates a partial stress-drop for immature fault zones and a complete stress drop for mature fault zones.

In our numerical simulations, slow-slip events are manifested as accelerated slip that fail to reach the seismic threshold velocity but release finite stress on the slip patch along a portion of the fault. The slip rate of slow slip events in our simulations can vary from $1 \times 10^{-8} \mathrm{~m} \mathrm{~s}^{-1}$ to $1 \times 10^{-4} \mathrm{~m} \mathrm{~s}^{-1}$ (Fig. 3). Besides slow-slip events, the events below the seismic threshold in our simulations also encompass aseismic creep and afterslip (Fig. 3b). Aseismic creep is characterized by slip rate that is close to the tectonic plate rate $(\leq$ $\left.1 \times 10^{-9} \mathrm{~m} \mathrm{~s}^{-1}\right)$. Afterslip is another category of transient slow-slip that releases stresses 
from recent earthquakes during the postseismic stage (Avouac, 2015; Bürgmann, 2018). The slip rate of afterslip is typically below the seismic slip rate of $1 \mathrm{~mm} \mathrm{~s}^{-1}$ and can go down to $1 \times 10^{-5} \mathrm{~m} \mathrm{~s}^{-1}$. Afterslip can be distinguished from the slow-slip events by when and where they occur, i.e., away from peak-slip regions of earthquakes.

Figs. 3a and $\mathrm{b}$ show the slip-rate evolution for a fault zone without and with healing during the seismic cycle. The simulation without healing (Fig. 3a) shows large surfacereaching ruptures that are periodic in time. This sequence of earthquakes encompasses dynamic events and aseismic creep but does not exhibit any slow-slip events between them. Fig. 3b shows a wider range of events including multiple slow-slip events in addition to earthquakes and creep. Such slow-slip events can be identified from the peak slip-rate function in these simulations (Figs. 2a and b, and Fig. 3d) and generally occur during the interseismic stage within the seismogenic zone in our simulations (Figs. $3 \mathrm{~b}$ and $\mathrm{d}$ ). These slow-slip events are distributed throughout the interseismic period, with no temporal preference before or after an earthquake, though they have a spatial preference in relation to the residual stresses from previous events. Earthquake ruptures and slow-slip events in our simulations with fault zone healing occur at the edges of previous ruptured region within the velocity-weakening zone (Fig. 3b), due to residual stress peaks from those events. The slow-slip events also contribute to the release of stresses during the interseismic period, and in addition, generate stress-peaks within the seismogenic zone, away from its base. This is in contrast to the simulation without healing (Fig. 3a), where the stress peaks are predominantly near the base of the seismogenic zone. Other numerical studies (Barbot, 2019b; Idini \& Ampuero, 2020) also showed that slow-slip events can be generated in the velocity-weakening part of the fault using quasi-dynamic continuum models. However, the relative size of seismogenic asperity to nucleation, $R_{u}$ (Barbot, 2019a), for such simulations is much lower than what we use here. Such numerical simulations can exhibit periodic slowslip events at lower $R_{u}$ values $(<1)$ and chaotic slow-slip events at higher $R_{u}$ values $(>13)$. Our simulations use an $R_{u} \sim 5$, which should result in periodic bilateral ruptures, as seen in Fig. 3a. Note that the incorporation of healing does not change the $R_{u}$ values significantly as they lie in the same parameter regime through time. However, interseismic healing helps release the stresses inelastically though time during the quasi-static deformation, which rearranges the stress-peaks and stress shadows along the fault dip, resulting in restriction of earthquake sizes and generation of slow-slip events.

Since the interseismic healing promotes slow-slip events, stresses are released nonuniformly along the fault during this period. This causes partial ruptures to terminate without reaching the free surface. Moreover, these slow-slip events delay the onset of subsequent earthquakes. We see in Figs. 3d and $\mathrm{f}$ that earthquakes become farther apart in time when there are slow-slip events between them, as compared to consecutive earthquakes occurring without such slow-slip events. This delay, combined with the occurrence of slow-slip events within the velocity-weakening region, gives rise to the irregular recurrence of earthquakes in immature fault zones with healing. We can also infer that the slow-slip events with higher amount of slip release more stresses during the interseismic period, which delays the subsequent earthquake by a larger amount (Fig. 3f).

Another notable feature of the simulation with healing is the penetration of aseismic creep into the velocity-weakening part of the fault (Fig. 3b). The simulation without healing (Figs. 3a and c) shows complete ruptures with regular recurrence intervals, and aseismic creep is constrained to the velocity-strengthening parts of the fault. However, the incorporation of healing during the interseismic period allows the creep to accumulate and build up progressively within the velocity-weakening region (Figs. 3b and d). We demonstrate the cumulative rupture and creep extent from all the events in our simulation with healing in relation to the velocity weakening and velocity strengthening regions along the fault on the right side of Fig. 3b. We see that the cumulative creep extends through almost the entire fault, whereas the earthquake rupture extent is predominantly confined to the velocity weakening region. Creeping within the seismogenic zone also causes nonuniform stress 
(a)

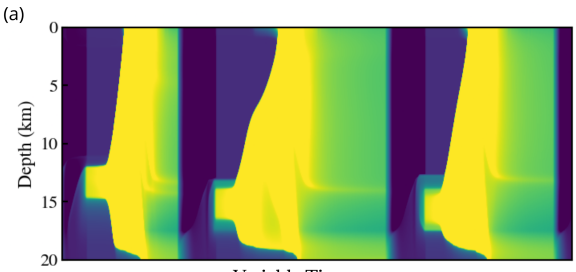

(c)
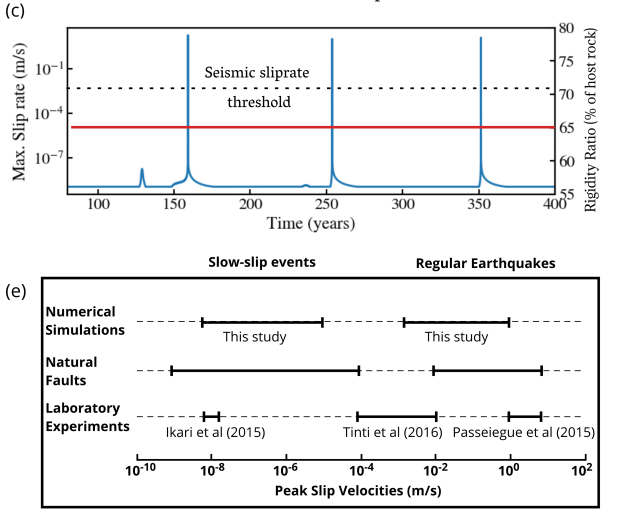

Adapted from Tinti et al (2016)
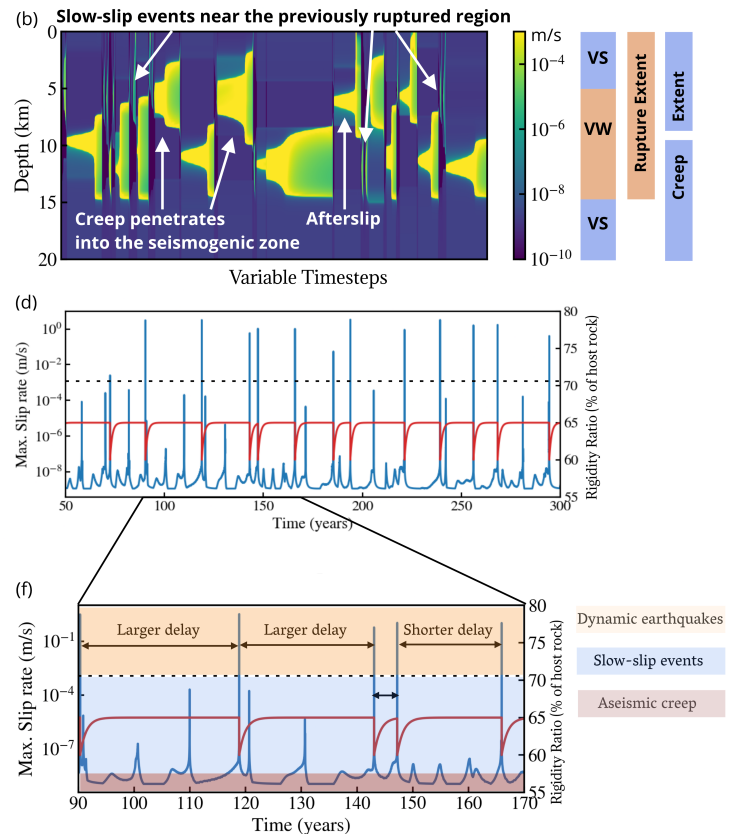

Figure 3. (a) The spatiotemporal slip-rate evolution in immature fault zone without healing (see color scale in (b)). (b) The spatiotemporal slip-rate evolution in immature fault zone with healing. The right side shows the depth extent of the frictional parameters delineating the velocityweakening and the velocity-strengthening region. (c-d) The rigidity ratio and the peak slip-rate function for a segment of the simulation. (e) A compilation of the peak slip-velocity range for slow-slip events from laboratory experiments, natural faults, and our numerical simulations. (f) Zoom in of part (d), showing larger delay in earthquake onset for higher slow slip-rates.

This effect of creep buildup within the velocity-weakening region and the abundance of slow-slip events is also observed in our simulation with permanent damage (Fig. A1). We observe more slow-slip events during the immature stage of the fault zone which is responsible for irregular recurrence intervals for earthquakes. These slow-slip events become less frequent during the mature stages of the earthquake cycle, and thus there is a more regular sequence of earthquakes. This transition is in accordance with the results from the previous section highlighting the differences between a mature and immature fault damage zone without permanent damage. We show the slip rate range of slow-slip events and fast earthquakes in our simulations, in comparison to those observed on natural faults and in laboratory experiments in Fig. 3e. We see that our numerical simulation of a fault zone with healing can produce a wide range of events, both in the fast slipping and slow slipping regime, comparable to those observed along natural faults.

\section{Discussions and Conclusions}

Seismologic and geodetic observations in immature fault zones exhibit complex ruptures and distributed coseismic damage. The damage zones in these faults are wider with poorly defined boundaries, resulting in earthquake sequences exhibiting irregular recurrence and size distributions akin to a Gutenberg-Richter magnitude scaling. Examples of such fault 
zones include the Ridgecrest sequence where geodetic studies have shown complex, multifault, and slow rupture with a heterogeneous static stress change (Goldberg et al., 2020). The study by DuRoss et al. (2016) along the immature Wasatch fault zone in Utah suggests partial-segment and multi-segment ruptures with irregular recurrence intervals. Seismic studies after the 2008 earthquake in Peloponnese, Greece have shown negligible surface deformation, i.e., a coseismic slip deficit towards the surface (Feng et al., 2010; Fielding et al., 2009). Dolan and Haravitch (2014) compiled multiple fault zone studies to show that the ratio of the surface slip-measurements to the slip at depth is correlated with fault zone maturity, and immature fault zones tend to have lower ratios. These studies imply that immature fault zones lack surface slip during the coseismic phase and exhibit irregular recurrence intervals, which is also corroborated by our models. In/contrast, very mature sections of fault zones have been shown to exhibit higher regularity in earthquake recurrence (e.g., Apline fault in Berryman et al. (2012); Howarth et al. (2021)).

Our results unveil how the seismic and aseismic segments in a fault zone interact during the earthquake cycle. We have shown that the seismogenic zone (velocity-weakening) in our models can have both seismic and aseismic slip episodes, with the latter encompassing slow-slip and creep events. The slow-slip events in our models are distributed within the velocity-weakening segment of the fault and occur throughout the interseismic period. Additionally, we see the aseismic creep penetrating into the velocity-weakening region in our immature fault zone models with healing. Both phenomena contribute to the nonuniform release of stresses during the seismic cycle, with slow-slip events having a dominant effect on the earthquake recurrence. Slow-slip events are very challenging to observe in geologically immature strike-slip faults using seismic or geodetic methods. Certain observations along strike-slip fault zones (e.g., the Northern SAF/in Murray et al. (2014)) and subduction zones (e.g., Japan subduction zone in K. M. Johnson et al. (2016)) have shown seismic and aseismic slip episodes occurring in the nominally velocity-weakening region. As subduction zones tend to be old and mature, some local geologic structures like heterogeneous seafloor structure or complex material properties associated with partially coupled subduction zone might be needed to rejuvenate them (Wang \& Bilek, 2014). Surface creep has been observed on several fault systems including the Maacama and Bartlett Springs (McFarland et al., 2009; Tong et al., 2013), and creep rates in the shallow parts can be locally very high in the order of $1 \times 10^{-6} \mathrm{~m} \mathrm{~s}^{-1}$ to $1 \times 10^{-9} \mathrm{~m} \mathrm{~s}^{-1}$ (Murray et al., 2014). This creep is suggested to extend to depths overlapping with some or all of the seismogenic zone in the Northern San Andreas fault system (Murray et al., 2014). Bruhat and Segall (2017) have explored models where they discuss that the updip propagation of deep interseismic creep can explain the slip rate profile along the Northern Cascadia subduction zone. These creep episodes may allude to slow-slip events happening in these regions of immature fault zones as well as subduction zones. Such conditions would be expected to extend the time between major earthquakes, and potentially also limit the earthquake size.

To summarize, we performed fully dynamic earthquake cycle simulations in a twodimensional strike-slip fault surrounded by an elastic damage zone with time-dependent shear modulus evolution that emulates coseismic damage and interseismic healing during seismic and aseismic periods respectively. The interseismic healing in immature fault zones can promote aseismic slip episodes including slow-slip events and creep to propagate into the seismogenic zone. Our numerical simulations show that such events in immature fault zones can limit the size of earthquakes and prolong the time between large earthquakes. In these simulations, slow-slip events are abundant and the stress peaks from previous earthquakes and slow-slip events are critical in determining the location of and timing of subsequent events, thereby creating irregularity in recurrence intervals and partial ruptures. These partial ruptures lead to predominantly sub-surface events in immature fault zones. In contrast, the higher compliance of mature fault zones leads to earthquakes with complete stress drops and rupture extending throughout the seismogenic zone. We demonstrate that such fundamental variations in fault-slip behavior can arise due to how the fault zone structure evolves in time, despite using simple elastic damage zone rheology and frictional fault properties. 
Our results emphasize the importance of monitoring seismic wave velocities and interseismic healing along active faults to help better characterize their first-order mechanical behavior.

\section{Acknowledgments}

This study was supported by the National Science Foundation (Grant Award EAR-1943742). We thank the editor - and the reviewers - for their helpful comments. We thank Dr. Roland Burgmann and Dr. Yoshihiro Kaneko for helpful discussions that significantly improved the quality of this manuscript. The code used to perform all the numerical simulations are available at: https://github.com/thehalfspace/Spear and citeable from https:// zenodo.org/badge/latestdoi/296673471.

\section{References}

Avouac, J.-P. (2015). From geodetic imaging of seismic and aseismic fault slip to dynamic modeling of the seismic cycle. Annual Review of Earth and Planetary Sciences, 43, 233-271.

Barbot, S. (2019a). Slow-slip, slow earthquakes, period-two cycles, full and partial ruptures, and deterministic chaos in a single asperity fault Tectonophysics, 768, 228171.

Barbot, S. (2019b, October). Slow-slip, slow earthquakes, period-two cycles, full and partial ruptures, and deterministic chaos in a single asperity fault. Tectonophysics, 768 , 228171. Retrieved 2021-04-30, from https://www.sciencedirect.com/science/ article/pii/S0040195119302781 doi: 10.1016/j.tecto.2019.228171

Ben-Zion, Y., \& Sammis, C. G. (2003). Characterization of fault zones. Pure and Applied Geophysics, 160(3-4), 677-715.

Berryman, K. R., Cochran, U. A., Clark, K. J., Biasi, G. P., Langridge, R. M., \& Villamor, P. (2012). Major earthquakes occur regularly on an isolated plate boundary fault. Science, 336(6089), 1690-1693.

Blanpied, M., Lockner, D., \& Byerlee, J. (1991). Fault stability inferred from granite sliding experiments at hydrothermal conditions. Geophysical Research Letters, 18(4), 609-612.

Brenguier, F., Campillo, M., Hadziioannou, C., Shapiro, N. M., Nadeau, R. M., \& Larose, E. (2008, September). Postseismic Relaxation Along the San Andreas Fault at Parkfield from Continuous Seismological Observations. Science, 321(5895), 1478-1481. Retrieved 2021-04-30, from https ://science.sciencemag.org/content/321/5895/ 1478 (Publisher: American Association for the Advancement of Science Section: Report) doi: 10.1126/science.1160943

Bruhat, L., \& Segall, P. (2017, October). Deformation rates in northern Cascadia consistent with slow updip propagation of deep interseismic creep. Geophysical Journal International, 211(1), 427-449. Retrieved 2021-04-30, from http://academic.oup.com/gji/article/211/1/427/4055607/ Deformation-rates-in-northern-Cascadia-consistent doi: 10.1093/gji/ggx317

Bürgmann, R. (2018). The geophysics, geology and mechanics of slow fault slip. Earth and Planetary Science Letters, 495, 112-134.

Cattania, C. (2019). Complex earthquake sequences on simple faults. Geophysical Research Letters, 46(17-18), 10384-10393.

Chen, K. H., Furumura, T., \& Rubinstein, J. (2015). Near-surface versus fault zone damage following the 1999 Chi-Chi earthquake: Observation and simulation of repeating earthquakes. Journal of Geophysical Research: Solid Earth, 120(4), 2426-2445. Retrieved 2021-04-30, from https : //agupubs . onlinelibrary .wiley.com/doi/abs/10.1002/2014JB011719 (_eprint: https://agupubs.onlinelibrary.wiley.com/doi/pdf/10.1002/2014JB011719) doi: https://doi.org/10.1002/2014JB011719

Dieterich, J. H. (1979). Modeling of rock friction: 1. experimental results and constitutive equations. Journal of Geophysical Research: Solid Earth, 84(B5), 2161- 
2168. Retrieved from https://agupubs.onlinelibrary.wiley.com/doi/abs/10 .1029/JB084iB05p02161 doi: 10.1029/JB084iB05p02161

Dolan, J. F., \& Haravitch, B. D. (2014, February). How well do surface slip measurements track slip at depth in large strike-slip earthquakes? The importance of fault structural maturity in controlling on-fault slip versus off-fault surface deformation. Earth and Planetary Science Letters, 388, 38-47. Retrieved 2021-04-30, from https:// WwW.sciencedirect.com/science/article/pii/S0012821X13006778 doi: 10.1016/ j.epsl.2013.11.043

DuRoss, C. B., Personius, S. F., Crone, A. J., Olig, S. S., Hylland, M. D., Lund, W. R., \& Schwartz, D. P. (2016). Fault segmentation: New concepts from the Wasatch Fault Zone, Utah, USA. Journal of Geophysical Research: Solid Earth, 121(2), 1131-1157. Retrieved 2021-04-30, from https://agupubs.onlinelibrary.wiley.com/doi/abs/10.1002/2015JB012519 (_eprint: https://agupubs.onlinelibrary.wiley.com/doi/pdf/10.1002/2015JB012519) doi: https://doi.org/10.1002/2015JB012519

Erickson, B. A., Jiang, J., Barall, M., Lapusta, N., Dunham, E. M., Harris, R., ... others (2020). The community code verification exercise for simulating sequences of earthquakes and aseismic slip (seas). Seismological Research Letters, 91(2A), 874-890.

Feng, L., Newman, A. V., Farmer, G. T., Psimoulis, P., \& Stiros, S. C. (2010, October). Energetic rupture, coseismic and post-seismic response of the 2008 MW 6.4 AchaiaElia Earthquake in northwestern Peloponnese, Greece: an indicator of an immature transform fault zone. Geophysical Journal International, 183(1), 103-110. Retrieved 2021-04-30, from https://doi.org/10.1111/j.1365-246X.2010.04747.x doi: 10 $.1111 /$ j.1365-246X.2010.04747.x

Fielding, E. J., Lundgren, P. R., Bürgmann, R., \& Funning, G. J. (2009). Shallow fault-zone dilatancy recovery after the 2003 bam earthquake in iran. Nature, 458(7234), 64-68.

Goldberg, D. E., Melgar, D., Sahakian, V. J., Thomas, A. M., Xu, X., Crowell, B. W., \& Geng, J. (2020). Complex Rupture of an Immature Fault Zone: A Simultaneous Kinematic Model of the 2019 Ridgecrest, CA Earthquakes. Geophysical Research Letters, $47(3)$, e2019GL086382. Retrieved 2021-04-30, from https : //agupubs . onlinelibrary.wiley.com/doi/abs/10.1029/2019GL086382 (_eprint: https://agupubs.onlinelibrary.wiley.com/doi/pdf/10.1029/2019GL086382) doi: https://doi.org/10.1029/2019GL086382

Gratier, J.-P., Favreau, P., \& Renard, F. (2003). Modeling fluid transfer along California faults when integrating pressure solution crack sealing and compaction processes. Journal of Geophysical Research: Solid Earth, 108(B2). Retrieved 2021-04-30, from https : //agupubs .onlinelibrary .wiley.com/doi/abs/10.1029/2001JB000380 (_eprint: https://agupubs.onlinelibrary.wiley.com/doi/pdf/10.1029/2001JB000380) doi: https://doi.org/10.1029/2001JB000380

Harris, R. A., \& Day, S. M. (1997). Effects of a low-velocity zone on a dynamic rupture. Bulletin of the Seismological Society of America, 87(5), 1267-1280.

Heaton, T. H. (1990, November). Evidence for and implications of self-healing pulses of slip in earthquake rupture. Physics of the Earth and Planetary Interiors, 64 (1), 1-20. Retrieved 2021-04-30, from https://www.sciencedirect.com/science/article/pii/ 003192019090002F doi: 10.1016/0031-9201(90)90002-F

Howarth, J. D., Barth, N. C., Fitzsimons, S. J., Richards-Dinger, K., Clark, K. J., Biasi, G. P., ... Sutherland, R. (2021). Spatiotemporal clustering of great earthquakes on a transform fault controlled by geometry. Nature Geoscience, 14(5), 314-320.

Huang, Y., \& Ampuero, J.-P. (2011). Pulse-like ruptures induced by low-velocity fault zones. Journal of Geophysical Research: Solid Earth, 116(B12). Retrieved from https:// agupubs.onlinelibrary.wiley.com/doi/abs/10.1029/2011JB008684 doi: 10 $.1029 / 2011 J B 008684$

Huang, Y., Ampuero, J.-P., \& Helmberger, D. V. (2014). Earthquake ruptures modulated by waves in damaged fault zones. Journal of Geophysical Research: Solid Earth, 119(4), 3133-3154. Retrieved 2021-04-30, from 
https://agupubs.onlinelibrary.wiley.com/doi/abs/10.1002/2013JB010724

(_eprint: https://agupubs.onlinelibrary.wiley.com/doi/pdf/10.1002/2013JB010724) doi: https://doi.org/10.1002/2013JB010724

Idini, B., \& Ampuero, J.-P. (2020). Fault-zone damage promotes pulse-like rupture and rapid-tremor-reversals.

Johnson, K. M., Mavrommatis, A., \& Segall, P. (2016). Small interseismic asperities and widespread aseismic creep on the northern Japan subduction interface. Geophysical Research Letters, 43(1), 135-143. Retrieved 2021-04-30, from https://agupubs.onlinelibrary.wiley.com/doi/abs/10.1002/2015GL066707 (_eprint: https://agupubs.onlinelibrary.wiley.com/doi/pdf/10.1002/2015GL066707) doi: https://doi.org/10.1002/2015GL066707

Johnson, P. A., \& Jia, X. (2005, October). Nonlinear dynamics, granular media and dynamic earthquake triggering. Nature, 437(7060), 871-874. Retrieved 2021-04-30, from https://www.nature.com/articles/nature04015 (Number: 7060 Publisher: Nature Publishing Group) doi: 10.1038/nature04015

Kaneko, Y., Ampuero, J.-P., \& Lapusta, N. (2011, October). Spectral-element simulations of long-term fault slip: Effect of low-rigidity layers on earthquake-cycle dynamics. Journal of Geophysical Research (Solid Earth), 116, B10313. doi: 10.1029/2011JB008395

Kaneko, Y., Lapusta, N., \& Ampuero, J.-P. (2008). Spectrál element modeling of spontaneous earthquake rupture on rate and state faults: Effect of velocity-strengthening friction at shallow depths. Journal of Geophysical Research: Solid Earth, 113(B9).

Kaproth, B. M., \& Marone, C. (2014). Evolution of elastic wave speed during shear-induced damage and healing within laboratory fault zones. Journal of Geophysical Research: Solid Earth, 119(6), 4821-4840. Retrieved 2021-04-30, from https://agupubs .onlinelibrary.wiley.com/doi/abs/10.1002/2014JB011051 (_eprint: https://agupubs.onlinelibrary.wiley.com/doi/pdf/10.1002/2014JB011051) doi: https://doi.org/10.1002/2014JB011051

Lapusta, N., Rice, J. R., Ben-Zion, Y., \& Zheng, G. (2000). Elastodynamic analysis for slow tectonic loading with spontaneous rupture episodes on faults with rate- and state-dependent friction. Journal of Geophysical Research: Solid Earth, 105(B10), 23765-23789. Retrieved from https://agupubs.onlinelibrary.wiley.com/doi/ abs/10.1029/2000JB900250 doi: 10.1029/2000JB900250

Lewis, M., Peng, Z., Ben-Zion, Y., \& Vernon, F. (2005). Shallow seismic trapping structure in the san jacinto fault zone near anza, california. Geophysical Journal International, 162(3), 867-881.

Lewis, M. A., \& Ben-Zion, Y. (2010). Diversity of fault zone damage and trapping structures in the parkfield section of the san andreas fault from comprehensive analysis of near fault seismograms. Geophysical Journal International, 183(3), 1579-1595.

Li, Y., Bürgmann, R., \& Zhao, B. (2020, January). Evidence of Fault Immaturity from Shallow Slip Deficit and Lack of Postseismic Deformation of the $2017 \mathrm{Mw} 6.5 \mathrm{Ji}-$ uzhaigou Earthquake. Bulletin of the Seismological Society of America, 110(1), 154-165. Retrieved 2021-04-30, from https://doi.org/10.1785/0120190162 doi: $10.1785 / 0120190162$

Li, Y.-G., Chen, P., Cochran, E. S., Vidale, J. E., \& Burdette, T. (2006). Seismic evidence for rock damage and healing on the san andreas fault associated with the $2004 \mathrm{~m}$ 6.0 parkfield earthquake. Bulletin of the Seismological Society of America, 96(4B), S349-S363.

Li, Y.-G., Vidale, J. E., Day, S. M., Oglesby, D. D., \& Cochran, E. (2003, April). Postseismic Fault Healing on the Rupture Zone of the 1999 M 7.1 Hector Mine, California, Earthquake. Bulletin of the Seismological Society of America, 93(2), 854-869. Retrieved 2021-04-30, from https://pubs.geoscienceworld.org/ssa/bssa/article/ 93/2/854/120884/Postseismic-Fault-Healing-on-the-Rupture-Zone-of (Publisher: GeoScienceWorld) doi: 10.1785/0120020131

McFarland, F. S., Lienkaemper, J. J., \& Caskey, S. J. (2009). Data from theodolite measurements of creep rates on San Francisco Bay region faults, California, 1979-2012 (USGS 
Numbered Series No. 2009-1119). Reston, VA: U.S. Geological Survey. Retrieved 202104-30, from http://pubs.er.usgs.gov/publication/ofr20091119 (Code Number: 2009-1119 Code: Data from theodolite measurements of creep rates on San Francisco Bay region faults, California, 1979-2012 Publication Title: Data from theodolite measurements of creep rates on San Francisco Bay region faults, California, 1979-2012 Reporter: Data from theodolite measurements of creep rates on San Francisco Bay region faults, California, 1979-2012 Series: Open-File Report) doi: 10.3133/ofr20091119

Mizuno, T., Kuwahara, Y., Ito, H., \& Nishigami, K. (2008). Spatial variations in fault-zone structure along the nojima fault, central japan, as inferred from borehole observations of fault-zone trapped waves. Bulletin of the Seismological Society of America, 98(2), $558-570$.

Murray, J. R., Minson, S. E., \& Svarc, J. L. (2014). Slip rates and spatially variable creep on faults of the northern San Andreas system inferred through Bayesian inversion of Global Positioning System data. Journal of Geophysical Research: Solid Earth, 119(7), 6023-6047. Retrieved 2021-04-30, from https://agupubs .onlinelibrary.wiley.com/doi/abs/10.1002/2014JB010966 (_eprint: https://agupubs.onlinelibrary.wiley.com/doi/pdf/10.1002/2014JB010966) doi: https://doi.org/10.1002/2014JB010966

Pei, S., Niu, F., Ben-Zion, Y., Sun, Q., Liu, Y., Xue, X., ... Shao, Z. (2019, May). Seismic velocity reduction and accelerated recovery due to earthquakes on the Longmenshan fault. Nature Geoscience, 12(5), 387-392. Retrieved 2021-04-30, from https://www. nature.com/articles/s41561-019-0347-1 (Number: 5 Publisher: Nature Publishing Group) doi: 10.1038/s41561-019-0347-1

Peng, Z., \& Ben-Zion, Y. (2006, March). Temporal Changes of Shallow Seismic Velocity Around the Karadere-Düzce Branch of the North Anatolian Fault and Strong Ground Motion. pure and applied geophysics, 163(2), 567-600. Retrieved 2021-04-30, from https://doi.org/10.1007/s00024-005-0034-6 doi: 10.1007/s00024-005-0034-6

Perrin, C., Manighetti, I., Ampuero, J.-P., Cappa, F., \& Gaudemer, Y. (2016). Location of largest earthquake slip and fast rupture controlled by along-strike change in fault structural maturity due to fault growth. Journal of Geophysical Research: Solid Earth, 121(5), 3666-3685. Retrieved from https://agupubs.onlinelibrary.wiley.com/ doi/abs/10.1002/2015JB012671 doi: 10.1002/2015JB012671

Rice, J. R. (1993). Spatio-temporal complexity of slip on a fault. Journal of Geophysical Research: Solid Earth, 98(B6), 9885-9907.

Rice, J. R., \& Ben-Zion, Y. (1996). Slip complexity in earthquake fault models. Proceedings of the National Academy of Sciences, 93(9), 3811-3818.

Roux, P., \& Ben-Zion, Y. (2014). Monitoring fault zone environments with correlations of earthquake waveforms. Geophysical Journal International, 196(2), 1073-1081. (Publisher: Oxford University Press)

Rubinstein, J. L., \& Beroza, G. C. (2005). Depth constraints on nonlinear strong ground motion from the 2004 parkfield earthquake. Geophysical Research Letters, 32(14).

Ruina, A. (1983). Slip instability and state variable friction laws. Journal of Geophysical Research: Solid Earth, 88(B12), 10359-10370. Retrieved from https://agupubs .onlinelibrary.wiley.com/doi/abs/10.1029/JB088iB12p10359 doi: 10.1029/ JB088iB12p10359

Scholz, C. H. (1998). Earthquakes and friction laws. Nature, 391 (6662), 37.

Snieder, R., Sens-Schönfelder, C., Ruigrok, E., \& Shiomi, K. (2016). Seismic shear waves as foucault pendulum. Geophysical Research Letters, 43(6), 2576-2581.

Taira, T., Silver, P. G., Niu, F., \& Nadeau, R. M. (2009, October). Remote triggering of fault-strength changes on the San Andreas fault at Parkfield. Nature, 461(7264), 636639. Retrieved 2021-04-30, from https://www . nature.com/articles/nature08395 (Number: 7264 Publisher: Nature Publishing Group) doi: 10.1038/nature08395

Thakur, P., Huang, Y., \& Kaneko, Y. (2020, August). Effects of Low-Velocity Fault Damage Zones on Long-Term Earthquake Behaviors on Mature Strike-Slip Faults. Journal of Geophysical Research: Solid Earth, 125(8). Retrieved 2021-04-30, from 
https://onlinelibrary.wiley.com/doi/10.1029/2020JB019587 doi: 10.1029/ 2020JB019587

Tong, X., Sandwell, D. T., \& Smith-Konter, B. (2013). High-resolution interseismic velocity data along the San Andreas Fault from GPS and InSAR. Journal of Geophysical Research: Solid Earth, 118(1), 369-389. Retrieved 2021-04-30, from https://agupubs.onlinelibrary .wiley.com/doi/abs/10.1029/2012JB009442 (_eprint: https://agupubs.onlinelibrary.wiley.com/doi/pdf/10.1029/2012JB009442) doi: https://doi.org/10.1029/2012JB009442

Vidale, J. E., \& Li, Y.-G. (2003, January). Damage to the shallow Landers fault from the nearby Hector Mine earthquake. Nature, 421(6922), 524-526. Retrieved 2021-04-30, from https://www.nature.com/articles/nature01354 (Number: 6922 Publisher: Nature Publishing Group) doi: 10.1038/nature01354

Waldhauser, F., \& Ellsworth, W. L. (2002). Fault structure and mechanics of the hayward fault, california, from double-difference earthquake locations. Journal of Geophysical Research: Solid Earth, 107(B3), ESE-3.

Wang, K., \& Bilek, S. L. (2014). Invited review paper: Fault creep caused by subduction of rough seafloor relief. Tectonophysics, 610, 1-24.

Wu, C., Peng, Z., \& Ben-Zion, Y. (2009, January). Non-linearity and temporal changes of fault zone site response associated with strong ground motion. Geophysical Journal International, 176(1), 265-278. Retrieved 2021-04-30, from https://doi.org/10 $.1111 /$ j.1365-246X.2008.04005.x doi: 10.1111/j.1365-246X.2008.04005.x

Zhao, P., \& Peng, Z. (2009). Depth extent of damage zones around the central calaveras fault from waveform analysis of repeating earthquakes. Geophysical Journal International, $179(3), 1817-1830$.

\section{Appendix A Model Details and Parameter Space}

Our damage evolution model is described by a change in the rigidity ratio with respect to the host rock. We parameterize this ratio of shear modulus of the damage zone to the shear modulus of the surrounding host rock using three variables: A: the coseismic damage accumulation, which shows the amount of damage increase after an earthquake, T: the healing time, which shows the interseismic duration it takes the fault zone to heal to its maximum level, and $\mathrm{P}$ : the permanent damage, which shows the amount of damage that the fault zone never recovers. The rigidity ratio evolves through time based on the following relation:

$$
\frac{\mu_{D}}{\mu}= \begin{cases}A_{0}, & \text { after each earthquake } \\ A\left(1-\exp \left(-T\left(t-t_{\text {start }}\right)\right)\right)+A_{0}, & \text { during interseismic period }\end{cases}
$$

where $t$ and $t_{\text {start }}$ are the current timestep and the start time of the previous earthquake in years, $\frac{1}{T}$ is the inverse of healing time (in years), $A_{0}$ is the prescribed damage after the earthquake. For the simulations with zero permanent damage (Fig. 2 and Fig. 3 ), $A_{0}$ is zero. For the simulation with permanent damage (Fig. A1), the permanent damage $P$ is set up by decreasing $A_{0}$ after each earthquake to $A_{0}-n P$, where $n$ is the earthquake number.

We use a spectral element method to simulate fully dynamic ruptures and aseismic deformation on a two-dimensional fault with mode-III rupture (Kaneko et al., 2011; Thakur et al., 2020). Adaptive time-stepping is used to switch from aseismic to seismic events based on a threshold slip velocity of $0.5 \mathrm{~mm} \mathrm{~s}^{-1}$ (Erickson et al., 2020). The fault is 24 $\mathrm{km}$ deep, with the seismogenic zone extending from $3 \mathrm{~km}$ to $16 \mathrm{~km}$. The rest of the fault creeps aseismically. Our two-dimensional rectangular domain is twice the fault-length in the dip direction and $30 \mathrm{~km}$ in the off-fault direction. The bottom of the fault is loaded with a plate loading rate of $35 \mathrm{mmyr}^{-1}$. Free surface is imposed on the top boundary of the domain, whereas the other three boundaries have absorbing boundary conditions. The frictional resistance of the fault to sliding is described by laboratory derived rate- and 
state-dependent friction laws, which were developed empirically (Dieterich, 1979; Ruina, 1983; Blanpied et al., 1991) and is widely used in numerical models to simulate earthquake sequences (Rice, 1993; Lapusta et al., 2000). We use rate- and state- dependent friction with aging law for the state-evolution to simulate earthquake sequences on the fault (Dieterich, 1979; Ruina, 1983; Scholz, 1998). We use the regularized form of the rate-and-state model (Lapusta et al., 2000; Rice \& Ben-Zion, 1996), which relates the shear strength $(T)$ to the slip rate $(\dot{\delta})$ as follows :

$$
T=a \bar{\sigma} \operatorname{arcsinh}\left[\frac{\dot{\delta}}{2 \dot{\delta_{o}}} e^{\frac{f_{o}+b \ln (\dot{\delta} \theta / L)}{a}}\right]
$$

where $\bar{\sigma}$ is the effective normal stress (i.e., the difference between lithostatic stress and the pore fluid pressure), $f_{o}$ is a reference friction coefficient corresponding to a reference slip rate $\dot{\delta}_{o}, L$ is the characteristic distance over which the contact asperity slips, and $a$ and $b$ are empirical constants dependent on the mechanical and thermal properties of the contact surface. The state variable $\theta$, interpreted as the average lifetime of the contact asperity, evolves as follows:

$$
\frac{d \theta}{d t}=1-\frac{\dot{\delta} \theta}{L}
$$

(Barbot, 2019a) has shown that the state variable $\theta$ is the age of contact strengthening. Depending on the values of $L,(a-b)$, and the ratio $\frac{a}{b}$, we can determine the frictional stability of the fault wherein we can have an unstable slip for a steady state velocity weakening frictional regime $(a-b<0)$, or a stable sliding for a steady state velocity strengthening frictional regime $(a-b>0)$. Fault dynamics is controlled by $R_{u}$, the ratio of the velocityweakening patch size to the nucleation size, and the ratio $\frac{b-a}{a}$ that controls the relative importance of strengthening and weakening effects and the ratio of static to dynamic stress drops. For higher values of $R_{u}$, we can obtain more chaotic rupture styles such as partial and full ruptures, aftershock sequence, and a wide range of events (Barbot, 2019a; Cattania, 2019). In our simulations, we use relatively/simple values for the theoretical nucleation size of $\sim 2 \mathrm{~km}$, and the width of velocity weakening region of $\sim 10 \mathrm{~km}$, implying that the value of $R_{u}$ is $\sim 5$, which predicts single-period full ruptures in a homogeneous medium (Barbot, 2019a).

The fault damage zone extends throughout the domain and is symmetric across the fault. We use temporal changes in the rigidity ratio of the fault damage zone for modeling the damage accumulation and healing through time. We use a constant half-width of 1 $\mathrm{km}$ for the fault zone geometry. This facilitates easier comparison between mature and immature fault zones and is coherent with the observations (Ben-Zion \& Sammis, 2003; Perrin et al., 2016). The host rock has a shear wave velocity of $3464 \mathrm{~km} / \mathrm{s}$ and a density of $2670 \mathrm{kgm}^{-3}$ implying that the shear modulus is $32 \mathrm{GPa}$. We start with the same initial shear wave velocity in the fault damage zone but with a density of $2500 \mathrm{kgm}^{-3}$ which remains constant throughout the simulation (Kaneko et al., 2008; Kaneko et al., 2011). Since density does not contribute as much to the rigidity as the shear wave velocity, any changes in the rigidity of the fault damage zone are directly related to the changes in shear wave velocity, which is an observable from seismic monitoring experiments. The initial rigidity ratio $\left(\frac{\mu_{D}}{\mu}\right)$ is approximately 0.94 , which primarily stems from the density difference between the host rock and the fault damage zone. The parameters tested for this study are discussed in table A1 and A2. The parameters shown in the results are shown in bold in table A2.

The time-evolution of the shear modulus, described in equation A1, is operative only during the quasi-static part of the deformation, i.e., when the inertia is negligible and the fault is creeping aseismically. Since the time-steps are large in this part of the simulation, the deformation is essentially slow-enough such that the stress-strain relationship is linear throughout the numerical simulation. During the dynamic earthquakes, the shear modulus remains constant till the inertial effects are dissipated, after which it drops by a prescribed amount. This ensures that we can study the effects of coseismic damage accumulation and 
interseismic healing using parameters inspired by seismic observations, but still pertain to an elastic deformation regime.

Table A1. Parameters used in numerical simulations of earthquake cycles. The normal and shear stresses represent the values for the velocity-weakening region.

\begin{tabular}{lll}
\hline Parameter & Symbol & Value \\
\hline Static friction coefficient & $\mu_{0}$ & 0.6 \\
Reference velocity & $V_{0}$ & $1 \times 10^{-6} \mathrm{~m} \mathrm{~s}^{-1}$ \\
Plate loading rate & $V_{p l}$ & $35 \mathrm{~mm} \mathrm{yr}^{-1}$ \\
Evolution effect & $b$ & 0.019 \\
Effective normal stress & $\bar{\sigma}$ & $50 \mathrm{MPa}$ \\
Initial shear stress & $\tau_{0}$ & $30 \mathrm{MPa}$ \\
Steady-state velocity dependence & & \\
in the seismogenic region & $(b-a)$ & -0.004 \\
Width of seismogenic zone & $W$ & $10 \mathrm{~km}$ \\
Half-width of damage zone & $W$ & $0,5 \mathrm{~km}$ \\
Average node spacing & $\mathrm{dx}$ & $20 \mathrm{~m}$ \\
Seismic slip-rate threshold & $V_{t h}$ & $1 \mathrm{~mm} \mathrm{~s}-1$ \\
Characteristic weakening distance & $L_{c}$ & $8 \mathrm{~mm}$ \\
Shear modulus of host rock & $\mu$ & $32 \mathrm{GPa}$ \\
Shear modulus of damaged rock & $\mu_{D}$ & Variable (see Eq. A1) \\
\hline & \multicolumn{2}{l}{}
\end{tabular}

Table A2. Damage evolution and healing parameters. The parameters in bold represent the simulations presented in the paper. The left column shows the range of rigidity ratio over which the shear modulus drops during earthquake and heals during interseismic period.

\begin{tabular}{ll}
\hline Rigidity ratio $\left(\frac{\mu_{D}}{\mu}\right)$ & Healing time $(\mathrm{yr})$ \\
\hline $40-45 \%$ & $\mathbf{8}, 10,12,15$ \\
$80-85 \%$ & $\mathbf{8}, 10,12,15$ \\
$60-65 \%$ & $4, \mathbf{8}, 10,20$ \\
$60-70 \%$ & 8 \\
$60-80 \%$ & 8 \\
\hline$y$
\end{tabular}

Figure A1 shows the fault-slip evolution in a simulation that includes permanent damage after each earthquake.

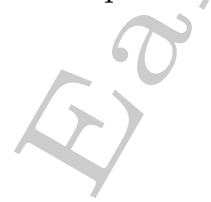



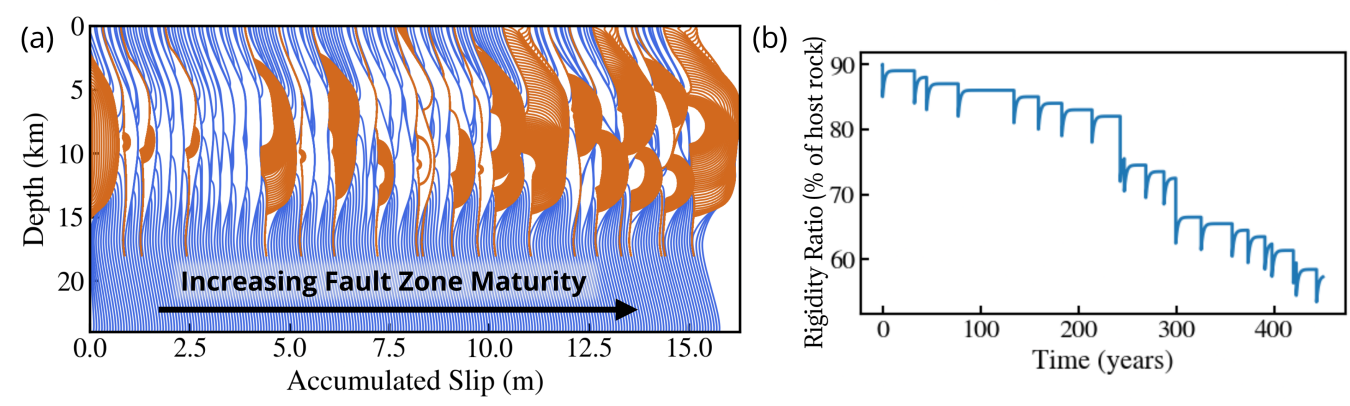

Figure A1. Incorporation of permanent damage after each earthquake demonstrates the transition from immature to mature fault zone. (a) The accumulated slip history. (b) Rigidity ratio through time. Here, the transition from immature to mature fault zone occurs within a few hundred years, whereas in nature, the evolution can take millions of years. 